\title{
Associated comorbidities, response to treatment and outcomes of young hypertensive patients attending a follow up clinic at Provincial General Hospital, Badulla
}

\author{
Liyanapathirana $C^{1}$, Mihirani AMS ${ }^{1}$, Widyarathne SC $^{1}$, Perera $\mathbf{C}^{2}$, Thasleem $\mathbf{S}^{2}$, Mahesh PKB
}

Journal of the Ceylon College of Physicians, 2021, 52, 87-93

\begin{abstract}
Introduction: There is a dearth of evidence on response to antihypertensive treatment among younger individuals with essential hypertension. The objective of this study was to describe the associated comorbidities and response to treatment in young hypertensive patients without complications at diagnosis who were attending VP/OPD clinic in Badulla Provincial General Hospital.
\end{abstract}

Methods: An observational retrospective longitudinal study was carried out with secondary data from 85 young (20-40 years) hypertensive patients with a follow up of at least 6 months. A pre-tested data extraction sheet was used. Descriptive analysis was followed by hypothesis testing with nonparametric tests at a significance level of $5 \%$.

Results: The median (IQR) age was 35 (33.5 to 38.0) years with male to female ratio being approximately 1:3. Median (IQR) follow up period was 46 (23 to $80)$ months. At enrolment median (IQR) systolic blood pressure (SBP) and diastolic blood pressure (DBP) were 150 (147.5 to 160.0) $\mathrm{mmHg}$ and 100 (100 to 100) $\mathrm{mmHg}$ respectively. There was no significant difference of the SBP and DBP between men and women $(P>0.05)$. In the follow up there was a significant reduction of the SBP and DBP of the total sample as well as of all three grades of hypertension (all $p<0.05$ ). There was a significant reduction of the total cholesterol and triglyceride (both $\mathrm{p}<0.05$ ). None in the grade 1 hypertension category, had developed any hypertension related events.
Conclusion: During the six months follow up period young hypertensive patients with essential hypertension had a good response to treatment.

Key words: young hypertensives, systolic blood pressure, diastolic blood pressure, essential hypertension, Sri Lanka

\section{Introduction}

Hypertension is among the major preventable risk factors leading to cardiovascular diseases (CVD) which is the number one cause of premature deaths worldwide. ${ }^{1}$ Elevated blood pressure significantly exerts its effects on the heart, brain, and kidneys, as well as a contributory factor to many other diseases contributing to majority of the deaths globally. Of the global population living with hypertension, more than two thirds live in low- and middle-income countries with a male predominance. ${ }^{2}$ Around $35 \%$ of the adult population in the South-East Asian region are hypertensive and it contributes to $9.4 \%$ of the total deaths. ${ }^{3}$ South Asians have a higher inherent potential of developing hypertension, along with diabetes, abdominal adiposity and CVDs compared to other regions in the world. ${ }^{4}$ The magnitude of hypertension has increased over the years with the age standardized prevalence increasing by $7.7 \%$ over a decade in lowand middle-income countries. ${ }^{5}$ Adequate control of hypertension has been a challenge with less than $20 \%$ of the patients having optimal control of the condition. $^{2}$

${ }^{1}$ Badulla Provincial General Hospital, Sri Lanka, ${ }^{2}$ Ministry of Heath, Sri Lanka.

Correspondence: CL, e-mail: chathuril@live.com

https://orcid.org/0000-0002-3889-0956

Received 07 September 2021, accepted 24 October 2021

This is an open-access article distributed under the terms of the Creative Commons Attribution License, which permits unrestricted use, distribution, and reproduction in any medium, provided the original author and source are credited. 
In the American Heart Association (AHA) guidelines, hypertension is defined as SPB of $\geq 140 \mathrm{~mm} / \mathrm{Hg}$ and/or a DBP of $\geq 90 \mathrm{~mm} / \mathrm{Hg}$ following repeated BP measurements among all adults (>18 years). ${ }^{6}$ The burden of hypertension has increased substantially from 1990 to 2015 and in 2015 14\% of all deaths and 143 million disability adjusted life years (DALYs) were associated with elevated SBP $>140 \mathrm{~mm} / \mathrm{Hg}^{7}$ This number further increases due to the contribution of hypertension to the deaths due to cardiovascular disease (54.5\% of IHD deaths), stroke (50\% of ischemic stroke and $58.3 \%$ of hemorrhagic stroke deaths $)^{7}$. Although hypertension is considered a disease prevalent among the advancing age group, it seems to be expanding to reach the relatively young population as well. The age that is considered as 'young' hypertension has been debatable with various guidelines presenting different cut offs including 30 , 40 and 50 years..$^{5-7}$ The complications of hypertension among the young ( $<40$ years) is highlighted by the increased risk of CVD's among this population com'pared to those less than 40 years who are normotensive. $^{8}$

The South Asian region including Sri Lanka, is facing an epidemic of chronic non-communicable diseases (NCD) owing to the demographic and epidemiological transitions. Men are the predominantly affected category while $21 \%$ of those with hypertension are not under any form of treatment for their condition. ${ }^{9}$ With the resurgence of NCD screening campaigns and routine medical checkup prior to employment, it has been found that the identification of young essential hypertension has increased over the years. Prevalence of hypertension in patients younger than 40 years of age found to be $17.4 \%$ in a cross-sectional populationbased survey done in Sri Lanka in $2014^{10}$ and the incidence was $5.7 \%$ in a different study done in 2014 in a tertiary care hospital in Sri Lanka. ${ }^{11}$

Diagnosis of hypertension among young population has been a challenge due to entities like whitecoat hypertension and spurious hypertension. ${ }^{12-18}$ Furthermore, treatment of young patients with hypertension has been quite a challenge, with current evidence through randomized trials arguing between for and against for the treatment of high normal blood pressure among this population due to the minimal benefits on the long run. ${ }^{15,16}$ Young adults between 20-39 years have shown to be least aware about having hypertension which imposes a delay in seeking treatment and poor control of blood pressure in this age group. ${ }^{19}$ Furthermore, the limited data available in this regard leaves clinicians cautious during the management of arterial hypertension among young hypertensives. ${ }^{20}$ On the contrary, overtreatment of low- risk patients have been a focus throughout the years ${ }^{21}$ which needs to be balanced between deciding who should be treated and who could be followed up closely. This has to be carefully assessed during the routine practice. ${ }^{22}$ Lifestyle modifications and/or pharmacological treatment are the main modalities of treatment of hypertension while considering the age of the patient and stage of disease along with the customized clinical judgement that would provide the required prognosis. ${ }^{23}$

The limitations among hypertension related data includes the paucity of evidence on the outcome of young hypertensives, considering them a difficult to reach population as they are the workforce of the country. This study sheds light on the outcomes of the patients who are diagnosed solely based on blood pressure measurements with no complications at the point of diagnosis, and the control of blood pressure through management protocols based on the current evidence available. This would further lead to provision of data for the local guidelines regarding hypertension among the young adult population, that has been a long-felt need. This study was carried out with the objective to describe the outcomes of uncomplicated young (20-40 years) hypertensive patients treated with antihypertensives at the VP/OPD clinic in Badulla Provincial General Hospital.

\section{Methods}

This retrospective observational longitudinal study was conducted at the VP/OPD clinic of the Provincial General Hospital Badulla. Medical records of the patients aged between 20 to 40 years who had a clinic follow up of at least 6 months were reviewed. Patients with complications at the point of diagnosis such as CVD events, stroke and peripheral vascular disease were excluded. Patients with diagnosed secondary hypertension and those with incomplete medical records were also excluded from the study. A minimum sample size of 82 was calculated by using the standard equation based on the comprehensive literature review ${ }^{24}$ and a $15 \%$ non-response rate was used to overcome the error.

A simple random sample was used from the eligible patients who were present at each day at the clinic using a computer-generated random number series from the Statistical Package for Social Sciences (SPSS) version 21. Data collection was done by experienced medical officers at the OPD clinic using a data extraction sheet that was filled following a thorough look into the medical records of each patient.

Systolic blood pressure $\geq 140 \mathrm{~mm} / \mathrm{Hg}$ and a 
diastolic blood pressure of $\geq 90 \mathrm{~mm} / \mathrm{Hg}$ was the cut off in diagnosing patients with hypertension in the 20-40 age category. The young hypertensives were categorized into three grades according to ESC 2018 BP classification.

Normality of numerical data was determined prior to analysis with graphical methods (i.e. histogram and P-P plots) and normality tests (i.e. Kolmogorov Smirnov and Shapiro Wilk test) and were found to be nonnormally distributed. Descriptive categorical data [e.g., occurrence of significant events such as stroke, hypertensive urgency, ischemic heart disease (IHD), peripheral vascular disease (PVD)] were presented using proportions and numerical data were presented with median and IQR. The associations of the groups with categorical outcomes were evaluated using the Chi square test. For the numerical associations of the independent groups, Mann Whitney $U$ test was used and for related samples, Wilcoxon Signed Rank test was used. Significance level was set at 0.05 level.

\section{Results}

A total of 85 participants were recruited to the study. The median (IQR) duration of follow up was 45.5 (22.8 to 79.5$)$ months.

\section{Demographic characteristics}

Most of the study sample were women 64 (75.3\%), with both men and women being diagnosed mostly in the $36-40$ year age category (52.4\% and $48.4 \%$ respectively) (Table 1 ). The median (IQR) age was 35 (33.5 to 38.0) years, 36.0 (33.0 to 37.5) years and 35.0 (33.3 to 38.0) years for the total sample, men, and women respectively. There was no statistically significant difference of the age between the men, and women $(p=0.882)$.

\section{Baseline clinical characteristics}

The systolic and diastolic blood pressure distributions were non-normally distributed. The summary statistics of the baseline blood pressure are shown in Table 2.

The median (IQR) BMI of the total sample was $28.0 \mathrm{~kg} / \mathrm{m}^{2}$ (25.0 to 30.3 ) and there was no statistically significant difference of the BMI between men and women $(P=0.905)$. The percentage of participants with diabetes was $3.53 \%$ (3 out of 85 ) and with LDL levels $>190 \mathrm{mg} / \mathrm{dl}$ was $8.06 \%$ (5 out of 62 ). Out of the men, $53.38 \%$ (11 out of 21 ) were smokers and $90.5 \%$ (19 out of 21) were using alcohol.

There was no statistically significant difference between the systolic $(p=0.796)$ and diastolic $(p=0.230)$ blood pressure between men and women. Among both men and women diagnosed with hypertension, majority belonged to the ESC grade $2(n=12 / 21$ and $n=43 / 64$ respectively).

\section{Follow up details and comparison with baseline parameters}

At the time of diagnosis, 76 (89.4\%) were started on one drug, $7(8.2 \%)$ on two drugs and the rest $(n=2$, $2.4 \%)$ on three drugs. At the end of the follow up, 34 (40.0\%) were on one drug, 26 (30.6\%) on two drugs, $19(22.4 \%)$ on three drugs, 5 (5.9\%) on four drugs and $1(1.2 \%)$ on five drugs. Regarding the consequences of hypertension, it was noted that 3 patients had experienced ischemic heart disease, one hypertensive emergency and hypertensive urgency. There was no stroke or peripheral vascular disease identified.

At the end of the follow up period, statistically significant improvement in the blood pressure was seen in both systolic and diastolic pressures which were statistically significant (both $\mathrm{p}<0.001$ ) (Table 3 ).

Table 1. Age and sex distribution of patients diagnosed with hypertension

\begin{tabular}{llcc}
\hline Age category & Men No. (\%) & Women No. (\%) & Total (\%) \\
\hline $21-25$ years & $0(0)$ & $2(3.1)$ & $2(2.4)$ \\
$26-30$ years & $2(9.5)$ & $5(7.8)$ & $7(8.2)$ \\
$31-35$ years & $8(38.1)$ & $26(40.6)$ & $34(40.0)$ \\
$36-40$ years & $11(52.4 \%)$ & $31(48.4)$ & $42(49.4)$ \\
Total & $21(100)$ & $64(100)$ & $85(100.0)$ \\
\hline
\end{tabular}


Table 2. Distribution of Systolic and diastolic blood pressure

\begin{tabular}{llll}
\hline BP & \multicolumn{1}{c}{$\begin{array}{c}\text { Males } \\
\text { Median (IQR) }\end{array}$} & \multicolumn{1}{c}{$\begin{array}{c}\text { Females } \\
\text { Median (IQR) }\end{array}$} & \multicolumn{1}{c}{$\begin{array}{c}\text { Total } \\
\text { Median (IQR) }\end{array}$} \\
\hline Systolic BP, mmHg & $\begin{array}{l}150.0 \\
(145.0 \text { to } 160.0)\end{array}$ & $\begin{array}{l}150.0 \\
(146.3 \text { to } 160.0)\end{array}$ & $\begin{array}{l}150.0 \\
(147.5 \text { to } 160.0)\end{array}$ \\
& & & \\
Diastolic BP, mmHg & 100.0 & 100.0 & 100.0 \\
& $(100.0$ to 100.0$)$ & $(100.0$ to 100.0$)$ & $(100.0$ to 100.0$)$ \\
\hline
\end{tabular}

Table 3. Baseline and follow up blood pressure

\begin{tabular}{llll}
\hline BP & \multicolumn{1}{c}{$\begin{array}{c}\text { Baseline } \\
\text { Median (IQR) }\end{array}$} & \multicolumn{1}{c}{$\begin{array}{c}\text { Follow up } \\
\text { Median (IQR) }\end{array}$} & $\begin{array}{c}\text { Significance of the } \\
\text { difference }\end{array}$ \\
\hline Systolic BP, mmHg & $\begin{array}{l}150.0 \\
(147.5 \text { to } 160.0)\end{array}$ & $\begin{array}{l}130.0 \\
(130.0 \text { to } 140.0)\end{array}$ & $\mathrm{P}<0.001^{*}$ \\
Diastolic BP, mmHg & $\begin{array}{l}100.0 \\
(100.0 \text { to } 100.0)\end{array}$ & $\begin{array}{l}80.0 \\
(80.0 \text { to } 80.0)\end{array}$ & $\mathrm{P}<0.001^{*}$ \\
\end{tabular}

*Statistically significant at 0.001 level

Once stratified according to the initial BP category there was a significant BP reduction (i.e. both SBP and DBP) in all three categories (Table 4).

Table 4. Distribution of baseline and follow up blood pressure measurements according to initial ESC BP grades

\begin{tabular}{lrrr}
\hline Initial BP grade & $\begin{array}{c}\text { Baseline } \\
\text { Median (IQR) }\end{array}$ & \multicolumn{1}{c}{$\begin{array}{c}\text { Follow up } \\
\text { Median (IQR) }\end{array}$} & $\begin{array}{c}\text { Significance of the } \\
\text { difference }\end{array}$ \\
\hline $\begin{array}{l}\text { Grade 1 } \\
\text { SBP, mmHg }\end{array}$ & $150.0(145.0$ to 150.0$)$ & $130.0(130.0$ to 140.0$)$ & $\mathrm{P}=0.007$ \\
DBP, mmHg & $90.0(90.0$ to 90.0$)$ & $80.0(80.0$ to 80.0$)$ & $\mathrm{P}=0.004$ \\
Grade 2 & & & \\
$\quad$ SBP, mmHg & $150.0(140.0$ to 160.0$)$ & $130.0(130.0$ to 140.0$)$ & $\mathrm{P}<0.001$ \\
DBP, mmHg & $100.0(100.0$ to 100.0$)$ & $80.0(80.0$ to 80.0$)$ & $\mathrm{P}<0.001$ \\
Grade 3 & & & \\
SBP, mmHg & $160.0(160.0$ to180.0) & $130.0(130.0$ to 140.0$)$ & $\mathrm{P}<0.001$ \\
DBP, mmHg & $110.0(110.0$ to 110.0$)$ & $80.0(80.0$ to 80.0$)$ & $\mathrm{P}<0.001$ \\
\hline
\end{tabular}


Table 5 shows the comparison of baseline and follow up measurements in relation to six selected parameters. There was significant reduction of the total cholesterol and triglycerides after the follow up period.

Table 5. Comparison of other baseline and follow up parameters

\begin{tabular}{|c|c|c|c|}
\hline & Baseline & Follow up & $\begin{array}{l}\text { Significance of the } \\
\text { difference ( } P \text { value) }\end{array}$ \\
\hline FBS (mmol/L) & $\begin{array}{l}5.1 \\
(4.7 \text { to } 5.3)\end{array}$ & $\begin{array}{l}5.0 \\
(4.5 \text { to } 5.4)\end{array}$ & 0.608 \\
\hline $\mathrm{TC}(\mathrm{mg} / \mathrm{dL})$ & $\begin{array}{l}200.0 \\
(177.0 \text { to } 223.8)\end{array}$ & $\begin{array}{l}195.5 \\
\text { (177.3 to 206.5) }\end{array}$ & $0.024^{*}$ \\
\hline $\mathrm{LDL}(\mathrm{mg} / \mathrm{dL})$ & $\begin{array}{l}125.5 \\
(107.5 \text { to } 146.0)\end{array}$ & $\begin{array}{l}128.5 \\
(102.5 \text { to } 142.5)\end{array}$ & 0.406 \\
\hline TG (mg/dL) & $\begin{array}{l}129.0 \\
(100.0 \text { to } 194.0)\end{array}$ & $\begin{array}{l}117.5 \\
\text { (93.0 to } 160.3)\end{array}$ & $0.013^{*}$ \\
\hline BMI $\left(\mathrm{kg} / \mathrm{m}^{2}\right)$ & $\begin{array}{l}28.0 \\
(25.0 \text { to } 30.3)\end{array}$ & $\begin{array}{l}27.0 \\
(25.0 \text { to } 29.0)\end{array}$ & 0.962 \\
\hline
\end{tabular}

*Statistically significant at 0.05 level

FBS = fasting blood sugar; $\mathrm{TC}=$ total cholesterol; $\mathrm{LDL}=$ low-density lipoprotein TG = triglyceride BMI = body mass index

When the hypertension-related events developed during the follow up are considered it was noted that in the hypertension grade 2 category, three developed ischaemic heart disease and one experienced a hypertensive emergency; in the hypertension grade 3 category one had a hypertensive urgency.

Table 6 shows the change of the ESC BP grade during follow up. Even though 74 (87.1\%) of the participants belonged to the hypertension grades 2 and 3 at the baseline, only 1 remained at grade 2 and 3 at the end of the follow up. All others were in normal or grade 1 categories.

Table 6. Change of the ESC BP grade during follow up

\begin{tabular}{lcc}
\hline Hypertension grade & At the point of diagnosis $N(\%)$ & At the end of follow up N (\%) \\
\hline Normal & 0 & $\begin{array}{l}53(62.3) \\
(5 \text { from stage 1, } 48 \text { from stage 2) }\end{array}$ \\
Grade 1 & $11(12.9)$ & $\begin{array}{l}31(36.5) \\
(7 \text { from stage } 1,24 \text { from stage 2) }\end{array}$ \\
Grade 2 and 3 & $74(87.1)$ & $1(1.2)$ \\
Total & $85(100.0)$ & $85(100.0)$
\end{tabular}




\section{Discussion}

This is the first documented Sri Lankan longitudinal study done on a cohort of young hypertensives. Both the systolic and diastolic blood pressures were significantly reduced in the follow up period among the young hypertensives, with appropriate t-reatment plans. In addition, the total cholesterol and triglyceride levels were significantly reduced.

There was a female predominance in the study sample. Firstly community-based evidence must be generated to evaluate whether this is due to a selection bias of the sample or whether the prevalence of hypertension is high among females between 20-40 years. In the case of a selection bias, the reasons may include the males being not bothered to seek treatment due to income-generation activities or the lack of awareness among them on the symptoms of hypertension at young age. If so, health promotional activities must target them ensuring that treatment seeking behaviour of men is improved.

Both systolic and diastolic blood pressure values were significantly reduced in the follow-up period. This reflects that if treated early, favorable results can be obtained in young hypertensives. Hence the educational programs are needed to ensure that the blood pressure measurements are being done in the general population including the youth. Currently, the Well Women Clinics at 35 years and 45 years as well as the Healthy Lifestyle Clinics from 35 years onwards, provide opportunities for the blood pressure measurements. Careful evaluations must be done to explore whether the age-related eligibility must be revised for the local setting. This can be done following more research studies at larger scales.

The total cholesterol level and triglyceride level showed a statistically significant reduction in the follow up period. Once the patients are being enrolled into the follow up, the holistic care can be provided creating the opportunity to manage other conditions like metabolic syndrome as well. ${ }^{25}$ The metabolic syndrome is being detected even in adolescents according to the global literature and its prevalence can be assumed to be rising with the lifestyle changes associated with risk factors like obesity. ${ }^{26,27}$

There were several limitations of the study. Even though the initial and the follow up blood pressure measurements were compared, the associated factors with the level of reduction and the effect of confounding factors were not assessed. This was a single-center study with a small sample size, and the primary aim was to generate some evidence on the utility of existing health care services in managing young hypertensives larger scale studies are needed for strengthening the findings of this study. Another limitation is that the compliance of the drug intake was assessed solely based on the information provided by the participants.

\section{Conclusions}

Young hypertensive patients with essential hypertension are amenable for a good control with expected good outcome.

\section{Recommendations}

Young hypertensives with essential hypertension should be detected when they have a relatively low risk at an early stage of hypertension. But these patients are often missed as they are asymptomatic. Routine screening in healthy lifestyle clinics, prior to university admissions, job enrollment and screening at department of motor traffic plays a major role in finding such patients. Once detected it is of utmost importance to educate these young hypertensives regarding proper follow up as it helps to achieve good control of blood pressure and the other associated risk factors.

\section{Conflict of interests}

Authors declare that they have no competing interests.

\section{Funding Statement}

This is a self-funded study.

\section{References}

1. GBD 2017 Causes of Death Collaborators (2018). Global, regional, and national age-sex-specific mortality for 282 causes of death in 195 countries and territories, 1980-2017: a systematic analysis for the Global Burden of Disease Study. Lancet. 2017; 392(10159): 1736-88.

2. World Health Organization (WHO). Hypertension 2021. Available from: https://www.who.int/news-room/factsheets/detail/hypertension. Accessed [20/6/2021]

3. Krishnani A, Gargii R, Kahandaliyanage A. Hypertension in the South-EastAsia Region: an overview. Regional Health Forum:WHO South EastAsia Region- Blood Pressure- Take control. 2013; 17(1): 1-83. Available from: WHO_regionalhealth-Forum_BP.pdfAccesed [20/06/2021].

4. Eapen D, Kalra GL, Merchant N, AroraA, Khan BV. Vascular Health and Risk Management Metabolic syndrome and cardiovascular disease in South Asians. Vascular Health and Risk Management. 2009. doi: https://www.dove press.com/ 
5. Mills KT, Stefanescu A, He J. The global epidemiology of hypertension. Nat Rev Nephrol. 2020; 16(4): 223-37.

6. Whelton PK, Carey RM, Aronow WS, Casey DE, et al. CC/ AHA/AAPA/ABC/ACPM/AGS/APhA/ASH/ASPC/NMA/PCNA guideline for the prevention, detection, evaluation, and management of high blood pressure in adults: a report of the American College of Cardiology/American Heart Association task force on clinical practice guidelines. Hypertension. 2018; 71: e13-e115. doi: 10.1161/HYP. 0000000000000065

7. Forouzanfar MH, Liu P, Roth GA, Ng M, Biryukov S, Marczak L, et al. Global Burden of Hypertension and Systolic Blood Pressure of at Least 110 to $115 \mathrm{~mm} \mathrm{Hg}, 1990-2015$. JAMA 2017; 317(2): 165-82.

8. Yano Y, Reis J P, Colangelo LA, Shimbo D. Association of Blood Pressure Classification in Young Adults Using the 2017 American College of Cardiology/American Heart Association Blood Pressure Guideline with Cardiovascular Events Later in Life. JAMA 2018; 320(17): 1774-82.

9. World Health Organization (WHO. Noncommunicable disease. Available from: https://www.who.int/news-room/ fact-sheets/detail/noncommunicable-diseases

10. Katulanda $P$, Ranasinghe $P$, Jayawardena $R$, Constantine GR, Rezvi Sheriff MH, Matthews DR. The prevalence, predictors and associations of hypertension in Sri Lanka: a cross-sectional population based national survey. Clinical and Experimental Hypertension 2014; 36(7): 484-91.

11. Ralapanawa U, Dharmaratne S, Jayawickreme K, Ekanayake M. Epidemiology of newly diagnosed hypertensives in a tertiary care hospital in a developing country. Clinical and Experimental Hypertension 2017; 39: 251-6.

12. Pickering T, Eguchi K, Kario K. Masked Hypertension: A Review. Hypertens Res. 2007; 30: 479-88.

13. Mahmud M, Feely J. Spurious systolic hypertension of youth: fit young men with elastic arteries. American Journal of Hypertension .2003; 16(3): 229-32.

14. Goodman H, Wilkinson JB, Carmel IM. Systolic Hypertension in Youth. 2019. 10.1007/978-3-319-75310-2_19

15. Yano Y, Stamler J, Garside DB, Daviglus ML, et al. Isolated Systolic Hypertension in Young and Middle-Aged Adults and 31-Year Risk for Cardiovascular Mortality: The Chicago Heart Association Detection Project in Industry Study. J Am Cardiol. 2015; 65 (4): 327-35.
16. Michael F. O'Rourke, Audrey Adji A, Namasivayam M, Interpreting Blood Pressure in Younger Adults. J Am Cardiol. 2015; 66(3): 329-30.

17 Dalal J, Sethi KK, Kerkar PG, Ray S, Guha S, Hiremath MS. Vascular Disease in Young Indians (20-40 years): Role of Hypertension. J Clin Diagn Res. 2016; 10(8): OE01-OE06. doi:10.7860/JCDR/2016/20204.8258

18. Kishi S, Teixido-Tura G, Ning H, Venkatesh BA, et al. Cumulative Blood Pressure in Early Adulthood and Cardiac Dysfunction in Middle Age: The CARDIA Study. J Am Cardiol. 2015; 25 (65): 2679-87.

19. De Venecia T, Lu M, Figueredo VM. Hypertension in young adults. Postgrad Med. 2016; 128(2): 201-7.

20. Williams B, Mancia G, Spiering W, Agabiti Rosei E, ESC Scientific Document Group. 2018 ESC/ESH Guidelines for the management of arterial hypertension. Eur Heart J. 2018; 39(33): 3021-104.

21. Furberg CD, Bekglunds G, Manolio TA, Psaty BM. Overtreatment and undertreatment of depression. J Intern Med. 1994; 235(5): 387-97.

22. Weber MA. Interpreting Blood Pressure in Young Adults. J Am Cardiol. 2015; 65(4): 336-8.

23. James PA, Oparil S, Carter BL, Cushman WC, et al. EvidenceBased Guideline for the Management of High Blood Pressure in Adults Report From the Panel Members Appointed to the Eighth Joint National Committee (JNC 8) Clinical Review and Education Special Communication 507. JAMA 2014; 311(5): 507-20.

24. Z Irmak, Duzoz G, Bozyer I. The effectiveness of a followup program on blood pressure and cardiovascular risk factors for hypertensive patients. Aust J of Adv Nurs. 2010; 28: 60-6.

25. Kassi E, Pervanidou P, Kaltsas G, et al. Metabolic syndrome: definitions and controversies. BMC. 2011; 48. doi: 10.1186/1741-7015-9-48

26. Poyrazoglu S, Bas F, Darendeliler F. Metabolic syndrome in young people. Curr Opin Endocrinol Diabetes Obes. 2014; 21(1): 56-63.

27. Mattsson N, Rönnemaa T, Juonala M, Viikari JS, Raitakari OT. The prevalence of the metabolic syndrome in young adults. The Cardiovascular Risk in Young Finns Study. J Intern Med. 2007; 261(2): 159-69. 